\section{A utopia da utopia}

Lúcia NAGIB. A utopia no cinema brasileiro: matrizes, nostalgia, distopias. São Paulo, CosacNaify, 2006. 216 páginas.

\section{Paulo Menezes}

"A queda do muro de Berlim em 9 de novembro de 1989 marca o fim da utopia socialista e a vitória do neoliberalismo pós-moderno e antiutópico". Dessa maneira Lúcia Nagib começa o livro A utopia no cinema brasileiro, no qual busca analisar filmes que marcaram simbolicamente, no cinema brasileiro, a utopia como projeto nacional.

Projeto ambicioso, como não poderia deixar de ser uma empreitada desse porte, vasculha, em seus seis capítulos, vários daqueles que se tornaram filmes de referência, nestas últimas quatro décadas, das esperanças e desesperanças de um país que mergulhou nos obscuros e dolorosos tempos da repressão, na ditadura militar, e que depois, com a anistia, avançou em direção ao fim do túnel que, dramaticamente, tem se mostrado mais longo do que se esperava, mais complexo do que devia e mais cheio de encruzilhadas do que se desejava.

O primeiro capítulo constrói-se tomando por base a análise de filmes ligados entre si pela permanência do mar como elemento simbólico, e já apresenta os marcos de sua proposta ao eleger sua referência analítica principal, pela qual propõe tanto o tema da utopia como os modos de simbolizá-lo no grande espetáculo de luz e cores do cinema: Deus e o diabo na terra do sol, de Glauber Rocha (1964, mas rodado em 1963). É lá que vamos encontrar o famoso refrão cantado por Sérgio Ricardo, "o sertão vai virar mar, e o mar vai virar sertão", que marcaria o imaginário de gerações ao se constituir como imagem, quando Manuel, materializando a realização da profecia que move o filme, desaparece no meio do mar revolto como se consumasse, nas palavras da autora, "a imolação do indivíduo em prol da transformação social" (p. 36). Não se deixa escapar, entretanto, que essa imagem de Glauber teria encontrado sua matriz no cinema francês da nouvelle vague, de François Truffaut, na cena final de Os incompreendidos, de 1959, quando Antoine Doinel, encarnado por aquele que seria durante tantos anos o ator predileto de Truffaut, Jean-Pierre Léaud, corre em direção a um mar que nunca vira, e para o qual acaba por não dar muito interesse. Se a cena de Glauber termina com uma tomada do mar revolto, a de Truffaut termina com um close no rosto ainda infantil de Antoine, marcando com este gesto a diferença entre a utopia coletiva e social do primeiro e a matriz individual e psicológica do segundo.

Esse filme, um marco na obra de Glauber Rocha, transforma-se, no decorrer do livro, na referência obrigatória com a qual será medida, inevitavelmente pela falta, todas as proposições que matizaram grandes filmes do cinema nacional nas últimas quatro décadas. É por isso que, neste mesmo capítulo, a autora analisa outro filme de Glauber, Terra em transe, realizado após o golpe militar, como sendo a matriz de uma corrente antiutópica que se desdobraria desde então e que aqui encontraria seu lugar simbólico inicial, com a subida ao poder de Porfírio Diaz, nome emprestado do ditador mexicano, alegorizando-se o golpe militar de 1964, que deitou por terra as transformações sociais e políticas que mobilizaram o Brasil desde os anos de 1950, mas que se transformaram no seu oposto: no lugar do socialismo revolucionário, um golpe militar que se auto-intitulou "revolução de 64", por uma sarcástica ironia.

O terceiro filme deste capítulo, Terra estrangeira, de Walter Salles (1995), é apresentado como aquele em que, após os malfadados anos do governo Collor, onde o exílio político foi substituído pela emigração por razões econômicas, "a imagem do mar tornado incapaz de conduzir o navio a seu destino torna-se de fato, central enquanto metáfora da perda da identidade" (p. 45). Aqui, como aponta a autora, a quebra da utopia teria se dado pela imagem televisiva, logo no início do filme, quando uma cena introduz o discurso da então ministra Zélia Cardoso de Melo, anunciando o tristemente célebre plano Collor, que confiscou as economias e a poupança de toda a população brasileira.

Por fim, a última parte desse capítulo analisa, de maneira breve, quatro filmes realizados na era pós-plano real, quando "novas esperanças começam a reanimar o cenário econômico e político do Brasil" (p. 49). São filmes que marcam o renascimento da Embrafilme e, com ela, de toda a produção nacional praticamente paralisada nos anos Collor: Corisco e Dadá, Baile perfumado e 
Crede-mi, lançados entre 1996 e 1997, e Abril despedaçado, de 2001.

O segundo capítulo, que tem o sugestivo título, "O centro, o zero e a utopia vazia", analisa os filmes Central do Brasil, Oprimeiro dia e Latitude zero, que, segundo Nagib, reformulam a utopia no cinema brasileiro na virada do milênio. No terceiro capítulo, temos revisitados os filmes Como era gostoso meu francês, Macunaima e Hans Staden, em que a imagem do mar remete a um aspecto importante do descobrimento e da constituição do Brasil como nação: o canibalismo. No quarto, um Brasil negro, e pobre, é trabalhado por meio das imagens de Orfeu, Orfeu negro e a peça de teatro Orfeu da Conceição, marcando o que a autora chamou de "O paraíso negro". Por fim, os dois últimos capítulos são dedicados cada um a apenas um filme, Cidade de Deus, que materializaria a utopia interrompida, e O invasor, representante elevado a típico da distopia dos anos contemporâneos.

Esta busca seqüencial, que elegeu a utopia como conceito de referência, a um só tempo primordial e essencial, poderia, à primeira vista, parecer um fio organizador dos problemas que os filmes de anos posteriores tematizaram e colocaram em questão, mas entretanto, no decorrer dos capítulos, vai se transformando de elemento iluminador em uma coerção analítica que impede, em alguns casos, de se tirar dos filmes as suas proposições mais instigantes e questionadoras para se interpretar os descaminhos por que passa o Brasil desses últimos anos. Nessa direção, ao eleger como referência política e cinematográfica inquestionável a utopia revolucionária dos anos de 1960, a autora calibra seu olhar tanto para o passado como para o futuro, sendo este segundo sempre visto com um déficit em relação aos sonhos e promessas irrealizadas de então. Assim, há de se perguntar se esse viés ideológico de princípio não faz a autora formular, em alguns casos, a pergunta errada para os filmes que enfrenta. Não seria mais produtivo, e mais instigante, ao invés de se questionar aonde foi parar a utopia perdida dos anos de 1960, tentar investigar, em seus desdobramentos, como a questão política e social é retrabalhada pelos olhos, e lentes, do presente? Ou seja, em vez de se pensar a sucessão entre utopia, utopia vazia, paraíso negro, utopia interrompida e distopia, como anunciam seus capítulos, não seria mais sugestivo perguntar como um projeto revolucionário, abortado pelas armas, desdobrou-se, após a esperança que tomou conta da nação com a anistia e com o fim da ditadura, em uma espécie de apatia social e assistencialismo saudosista após duas reeleições de colorações a priori diversas, mas de resultados assustadoramente aproximados?

Pensar a utopia dos anos de 1960 como ponto de partida, e de chegada, faz com que em alguns capítulos o leitor seja tomado por uma sensação de que só se pode pensar o Brasil a partir desse ângulo. Esse estranhamento surge já no primeiro capítulo, quando a autora afirma que Terra estrangeira mostra que "essas pessoas sensíveis, claramente deslocadas em seus afazeres indignos de garçonete ou traficante no exílio, merecem uma nova chance" (p. 48). Conclusão no mínimo curiosa, para um filme que termina com o casal indo para a fronteira de Portugal, Paco baleado, deitado e sangrando à beira da morte, que sem dúvida ocorrerá, seguida da cena final onde um músico cego, tocando no metrô, não percebe que sua caixa de violinos, na qual havia sido deixado um punhado de diamantes, é derrubada no chão. Observamos desolados que suas duas moedas, além dos diamantes, são pisados pela multidão que nada vê, até se perderem por completo. Difícil vislumbrar aqui a possibilidade, mesmo que remota, de uma nova chance, como afirmou Nagib.

Da mesma forma, no capítulo 3 - que remete a dimensão antropofágica de Como era gostoso meu francês à antropofagia dos modernistas dos anos de 1920, - isso é realizado sem muitas mediações, necessárias caso se queira comparar o período mais cruel da ditadura militar, seus anos pós-AI-5, imersos no quase canibalismo de uma nação politicamente ditatorial aprofundada em seu capitalismo dependente, para usar os termos da época, com o projeto modernista de 22 , de busca da constituição do Brasil enquanto nação em suas relações com a ex-metrópole e a Europa. Nessa perspectiva, a questão da utopia mostra-se um pouco deslocada, pois não é disso que tratam os modernistas, não é isso que visa seu projeto. À parte essa associação um tanto extemporânea, esse capítulo tem sugestivas análises dos filmes e dos mitos fundantes do Brasil como nação.

O mesmo acontece no capítulo "Paraíso negro". Novamente a utopia como conceito de refe- 
rência promove afirmações um pouco deslocadas, para dizer o mínimo. Neste, como em outros momentos, confunde-se, na caracterização dos morros como lugares onde se vive bem e sem problemas, uma harmonia social bem realizada com uma utopia de democracia racial. Confunde-se, portanto, harmonia com utopia, esquecendo-se, como aponta Durkheim, que ambas não são sinônimos. É claro que Orfeu se distancia dos filmes políticos dos anos de 1960. Mas não por ser uma "ilha utópica", como afirma a autora, por apresentar uma pretensa "realidade" ao mostrar o lado "negativo" do morro, mas por ser, como em várias obras anteriores de Cacá Diegues, a busca de uma harmonia, tão ridiculamente caracterizada em Xica da Silva, então reapresentada pela possibilidade de uma saída individual para um inferno social. Assim, a visão positiva e idealizada da favela, parece-me, nada tem a ver com qualquer projeto utópico, mas diz muito mais a respeito da possibilidade de instauração de uma sociedade livre da luta de classes e dos conflitos sociais, aqui associados a raciais. Deixando isso de lado, o capítulo ganha corpo quando se propõe a buscar as raízes de nosso Orfeu, revisitando o mito grego, a peça de Vinícius de Moraes, o filme de Camus (realizado a partir da peça) e os escritos de Sartre. Lá vemos que a associação entre cultura negra e uma certa naturalização encontrou em terras européias algumas de suas mitificações, primas-irmãs de nosso mito de igualdade racial e inexistência de racismo.

Os dois últimos capítulos, também por se dedicarem cada um a apenas um filme, são os melhores do livro, com análises mais densas e, portanto, mais sugestivas. O viés inicial reaparece na afirmação de que, em Cidade de Deus, o "realismo interrompe o percurso utópico" (p. 141) e que Ivan, de O invasor, se "vê atormentado pelo fim do sonho utópico" (p. 175). Nesses casos, entretanto, a análise vai mais fundo e não se deixa contaminar por essa busca que, de antemão, já se sabe nada de utópico encontrará. São dois capítulos de muito interesse, pois as análises do primeiro colocam em questão muitas das análises da época que reduziam o filme a uma estetização da violência, sem perceber com isso as inúmeras questões que justamente a mudança da forma fazia com que a reflexão fosse transportada para outras dimensões que não apenas as da pobreza e do tráfico.
No caso de $O$ invasor, pode-se estranhar a escolha da autora. Muito mais pertinente - se abandonarmos o caminho utopia-distopia para lançarmos um olhar sobre os desdobramentos simbólicos de um Brasil que parece cada vez mais condenado a realizar o famoso refrão dos anos de 1970, de ser o eterno "país do futuro", e nunca do presente - seria a autora ter escolhido o filme Cronicamente inviável, de Sérgio Bianchi, que é citado comparativamente duas vezes, mas nunca de fato analisado durante todo o livro. Difícil pensar em relação a este filme qualquer tipo de utopia ou mesmo distopia, no que provavelmente se devem creditar as razões de seu esquecimento.

Por tudo isso, o título do livro aparece como um referencial que se transforma, página a página, em uma ligeira camisa de força. Ligeira, pois se deixarmos de lado os momentos em que buscar ler os filmes por essa perspectiva causa certo estranhamento no leitor, com referências às condições políticas e sociais do Brasil um pouco rápidas e diretas, somos brindados por interessantes análises que interpretam os desdobramentos do cinema pós-utópico (um termo mais apropriado) a partir dos anos de 1970, quando a questão da utopia não se apresentava mais como problema. É pena que, por outro lado, várias outras pistas e sugestões que esses filmes instigam, e que às vezes estão mesmo em seu cerne, como no caso de Terra estrangeira, entre outros, tenham sido deixadas de lado por essa busca infrutífera que acabou por fazer, no decorrer da obra, a procura da utopia perdida se transformar em sua própria e derradeira utopia.

\section{PAULO MENEZES é professor do Departamen- to de Sociologia da FFLCH - USP. E-mail: paulomen@usp.br}

